\title{
Ameliorating Effect of Piperine on NO-cGMP Pathway in Stress Induced Depression
}

\author{
Harshita Jain $^{1 *}$, Prateek Jain ${ }^{2}$, Bharti Ahirwar ${ }^{3}$ and Dheeraj Ahirwar ${ }^{1}$ \\ ${ }^{1}$ School of Pharmacy, Chouksey Engineering College, Bilaspur- 495004, C.G, India \\ ${ }^{2}$ ADINA Institute of Pharmaceutical Sciences, Sagar-470002, Madhya Pradesh, India \\ ${ }^{3}$ Department of Pharmacy, Guru Ghasidas Central University, Bilaspur- 495004, C.G, India
}

\begin{tabular}{|c|c|}
\hline Abstract & Article Information \\
\hline \multirow{4}{*}{$\begin{array}{l}\text { Depression has become a common illness among individuals of every age group. Among } \\
\text { numerous factors held responsible for depression stress is most vital. Behind the specified } \\
\text { disorder various hypothesis has been laid out where Nitric Oxide is emerging target to treat } \\
\text { stress induced depression. Antidepressant potential of piperine in stressed and unstressed } \\
\text { condition was evaluated using tail suspension test and forced swim test whereas locomotor } \\
\text { activity was evaluated by actophotometer. Results of the present study indicate the potential } \\
\text { of antidepressant effect of piperine in stress. Methylene blue potentiated the effect of sub- } \\
\text { effective dose of PP and SB-203580 enhanced effect of Piperine in stressed mice with no } \\
\text { array on locomotor activity with direct influence on Nitric oxide. Piperine produced significant } \\
\text { changes in Nitric oxide level which is pathophysiologic mediator(s) of depression, which } \\
\text { validate the action of piperine on depression symptoms. }\end{array}$} & \begin{tabular}{ll}
\multicolumn{3}{l}{ Article History: } \\
Received $: 01-02-2015$ \\
Revised $: 19-03-2015$ \\
Accepted $: 25-03-2015$
\end{tabular} \\
\hline & $\begin{array}{l}\text { Keywords: } \\
\text { Depression } \\
\text { Piperine } \\
\text { Nitric oxide }\end{array}$ \\
\hline & $\begin{array}{l}\text { *Corresponding Author: } \\
\text { Harshita Jain }\end{array}$ \\
\hline & \\
\hline
\end{tabular}

\section{INTRODUCTION}

Depression is a debilitating illness with an increasing morbidity and mortality. Furthermore, world health organization revealed that depression is the fourth leading cause of disability worldwide, exceeded by lower respiratory infections, perinatal conditions and HIVIAIDS (World Health Organization, 2001). Clinical studies showed elevated plasma nitrate levels and increased nitric oxide synthase (NOS) expression in the hippocampus of depressed patients (De Oliveira et al., 2000, 2008).

Stress has long been observed to play a role in the etiology of neurodegenerative diseases and mental disorders (Esch et al., 2002). Restrain stress induces a generalized increase in the production of Nitric Oxide (NO) and cause anxious behavior in rodents (Sevgi et al., 2006). Immobilization-induced stress has been observed to significantly increase an expression of Nitric Oxide Synthases (NOS) in rodents (Madrigal et al., 2002; Tsuchiya et al., 1997).

Nitric oxide (NO), which is an important neurotransmitter in the nervous system, (Baranano et al., 2001) is synthesized from L-arginine aminoacid by the NOS enzyme (Schuman and Madison, 1994). Nitric oxide, an intercellular messenger in the brain, plays an important role in various physiological and pathological processes (Gow et al., 2004). It is a short lived, lipophilicmolecule generated from L-arginine, by various NADPH-dependent enzymes called NOS. There are three NOS isoforms in the NOS family, termed neuronal NOS, inducible NOS, and endothelial NOS (Michel \& Feron, 1997). It plays an important role in regulating many behavioural, cognitive and emotional processes such as learning, aggression, locomotion, anxiety and depression (Dzoljic et al., 1997; Harkin et al., 1999; Holscher 1997; Nelson et al., 1995; Wiley et al., 1995). In recent studies, inhibition of NOS enzyme elicited antidepressant-like behavioural effects in several animal experiments (Harkin et al., 1999; Jefferys and Funder, 1996; Da Silva et al., 2000; Yildiz et al., $2000 a, b)$ and this effect was reversed by NOS substrate L-arginine suggesting that NO plays an important role in these behavioural responses (Harkin et al., 1999; Jefferys and Funder, 1996; Yildiz et al., 2000a,b). Further, NOS activity is involved in the mechanism of action of several antidepressants. For example, the selective serotonin reuptake inhibitor paroxetine inhibits in vitro NOS activity and decreases plasma nitrite and nitrate levels significantly in depressed patients (Finkel et al., 1996), whereas chronic therapy with imipramine or citalopram did not change NOS activity in the examined brain regions (cortex, hippocampus or cerebellum) (Jopek et al., 1999). Furthermore, Wegener et al., 2003 showed that, serotonergic antidepressants; paroxetine, citalopram and tianeptine and mixed serotonergic-noradrenergic antidepressant; imipramine decreased hippocampal NOS activity in vitro in rats although they don't have direct effects on NOS under clinically relevant conditions. It seems that there are controversial results for the effects of different antidepressants on NOS activity but the actions 
Harshita Jain et alo,

on NOS are common to a variety of structurally dissimilar serotonergic antidepressants. Further, iNOS-derived NO activates an endogenous NO-sensitive guanylyl cyclase, resulting in increased levels of cGMP (Snyder and Bredt, 1991; Nagao et al., 2003; André et al., 2005).

Immobilization is one of the best explored models of stress in rodents as this model combines both emotional (escape reaction) and physiological (muscle work) stress (Bhattacharya and Bhattacharya, 1982). Forced immobilization is one of the best explored models of stress in rodents. This model combines emotional stress (escape reaction) and physiological stress (muscle work), resulting in both restricted mobility and aggression. As painful stimuli are not directly involved in restraint stress, this form of stress is probably more akin to physiological stress (Bhattacharya and Bhattachatyya, 1982). Stress initiates a series of underlying mechanisms and cascades and one of the several implicated chemicals that is elevated after stress is NO (Esch et al., 2002). Immobilization stress as long as $6 \mathrm{~h}$ is well reported to activate the release of TNF- $\alpha$ through activation of NFkappa B (Madrigal et al., 2002). TNF- $\alpha$ activates the mitogen-activated protein kinase (MAPK) pathways p42/p44 MAPK, JNK/SAPK, and p38, the last of which is responsible for interleukin-6 production (Paola et al., 1999). Thus, immobilization stress is hypothesized to involve activation of p38 MAPkinase and consequently induce the symptoms of depression and increase the duration of immobility in relevant behavioral models of depression like FST and TST. This immobilization stressinduced depression has been reported y earlier studies too (Sevgi et al., 2006).

Selective serotonin re-uptake inhibitors are believed to exert their clinical antidepressant effects by blocking the re-uptake of serotonin at the synapse, resulting in an elevation of extracellular serotonin concentrations in brain. Fluoxetine is one of the most currently used antidepressant among this group of drugs. Fluoxetine prevented the stress-induced deficit in the grooming behaviour in the splash test. Fluoxetine also significantly decreased the attack frequency when compared to the stressed control group in the resident-intruder test. These results support the assumption that NOS inhibitors can be a new class of antidepressant drugs possibly acting on neuronal NOS (Mutlu et al., 2009). Further, NOS inhibitors being a class of drugs, acting on enzyme level may prove to be better agents, devoid of any long term changes in cellular biochemistry and bring behavioral stigmas like dependence or withdrawal syndromes.

\section{MATERIAL AND METHODS}

Swiss albino mice (22-30 g) were employed in the study. Animals were procured from DRDE, Gwalior, India. Animals were housed under laboratory conditions with alternating light and dark cycles of $12 \mathrm{~h}$ each. They had free access to food and water. The animals were acclimatized to the laboratory conditions before behavioral experiments. The experimental protocol was approved by the Institutional Animal Ethics Committee with registration number 1546/PO/a/11/CPCSEA and care of the animals

Fluoxetine was obtained from Cadila Pharmaceuticals, Ahmedabad. Piperine, Methylene Blue and SB-203580 were obtained from sigma Chemicals.
Sci. Technol. Arts Res. J., Jan-March 2015, 4(1): 109-114

Tail suspension test was performed according to the method described by Steru et al. (1985) and Forced swim test was proposed as a model to test antidepressant activity by Porsolt et al. for evaluating potential antidepressants. The total duration of immobility was observed (Bhutani et al., 2008).

The effect of various treatments on locomotor activity was observed in actophotometer (Inco, Ambala, India). The locomotor activity scores for each animal were recorded for a period of $10 \mathrm{~min}$ (Gilhotra and Dhingra, 2009).

For nitrite estimation, blood was withdrawn from tail vein of mice immediately before setting the animal free and subjecting it to behavioral tests in all the groups. The sampling procedure was completed during immobilization to avoid the extra stress incurred upon mice during an altogether a new procedure of mouse immobilization for handling the tail of mice. Plasma was separated using cooling centrifuge at 2500 r.p.m. for $10 \mathrm{~min}$. It was stored in refrigerator and processed for nitrite estimation within 24 hrs. Plasma nitrite was measured by spectrophotometric assay based on Griess reaction (Green et al., 1982, Gilhotra and Dhingra, 2009).

Twenty two groups of mice were employed in the study. Each group consisted of 6 mice. Stress was produced in them by immobilizing for $6 \mathrm{~h}$. Mice subjected to immobilization were called as stressed mice and mice not subjected to immobilization were called as unstressed mice and has been mentioned accordingly. Behavioral testing was performed carefully in a stepwise manner i.e. mice in each group were subjected to three tests (Dunn et al., 2005): (a) Tail Suspension Test; then a 6 min rest in home cage, there after (b) locomotor activity test in actophotometer, again followed by 6 min rest, and then (c) Forced Swim Test. All the drugs were administered intraperitoneally (i.p.) $30 \mathrm{~min}$ before the behavioral testing in unstressed group and immediately before immobilization in stressed group. When combinations of the drugs were employed, pretreatments were administered 15 min before the administration of the other drug. For nitrite estimation blood samples were collected before subjecting the mice to behavioral testing. All statistical analysis has been done using one-way analysis of variance (ANOVA) followed by Tukey's test in the Graph Pad Instat (GPIS) package, version 3.05.

\section{RESULT}

Study showed that immobilization stress has marked effect on depression and piperine decreased immobility time in stressed condition at $10 \mathrm{mg} / \mathrm{kg}$ and $20 \mathrm{mg} / \mathrm{kg}$ but in unstressed condition piperine has no significant effect in immobility time (Table 1). This indicated significant antidepressant effect of piperine in stressed condition.

Different treatments provided to stressed group showed different effects. Methylene blue $(15 \mathrm{mg} / \mathrm{kg})$ has no significant effect on immobility time as compared to immobilized group but combination of methylene blue $(15 \mathrm{mg} / \mathrm{kg})$ and subeffective dose PP $(10 \mathrm{mg} / \mathrm{kg})$ and effective dose $(20 \mathrm{mg} / \mathrm{kg})$ significantly decreased immobility time in TST and FST (Figure 1). 
Table 1: Effect of piperine on Immobility time in stressed as well as unstressed mice expressed in seconds in Forced swim test as well as Tail Suspension Test

\begin{tabular}{cccc}
\hline \multirow{2}{*}{ Treatment } & Dose & \multicolumn{2}{c}{ Duration of Immobility (sec) (Mean \pm SE) } \\
\cline { 2 - 4 } & & Forced swim test & Tail suspension test \\
\hline VEH(UnS) & $10 \mathrm{ml}$ & $144.7 \pm 7.2$ & $188.5 \pm 10.6$ \\
IM & $10 \mathrm{ml}$ & $215 \pm 11.3^{\mathrm{a}}$ & $234.2 \pm 12.3^{\mathrm{a}}$ \\
PP U & 5 & $139.3 \pm 8.5$ & $174.3 \pm 8.5$ \\
PP U & 10 & $143.0 \pm 13.1$ & $175.0 \pm 11.1$ \\
PP U & 20 & $147.9 \pm 10.3$ & $182.9 \pm 7.3$ \\
PP S & 5 & $182.0 \pm 10.5$ & $192.3 \pm 16.5$ \\
PP S & 10 & $164.0 \pm 7.8^{\mathrm{b}}$ & $185.2 \pm 10.8^{\mathrm{b}}$ \\
PP S & 20 & $121.2 \pm 9.3^{\mathrm{c}}$ & $148.0 \pm 15.3^{\mathrm{c}}$
\end{tabular}

In Tail Suspension Test. $\mathrm{n}=6$ in each group. Values are expressed as Mean \pm S.E. Data was analyzed by one way ANOVA followed by Tukey's Post Hoc Test. In Forced Swim test $F(7,40)=40.90 ; p<0.0001, a=p<0.001$ significant difference from unstressed group, $b==p<0.001$ significant difference from immobilized group, $c=p<0.001$ significant difference from immobilized group. In Tail Suspension Test $F(7,40)=24.39 ; p<0.001, a=p<0.001$ significant difference from unstressed group, $b==p<0.001$ significant difference from immobilized group, $c=p<0.001$ significant difference from immobilized group. UnS: unstressed, IM: Immobilization, PP: Piperine. Doses mentioned are in $\mathrm{mg} / \mathrm{kg}$
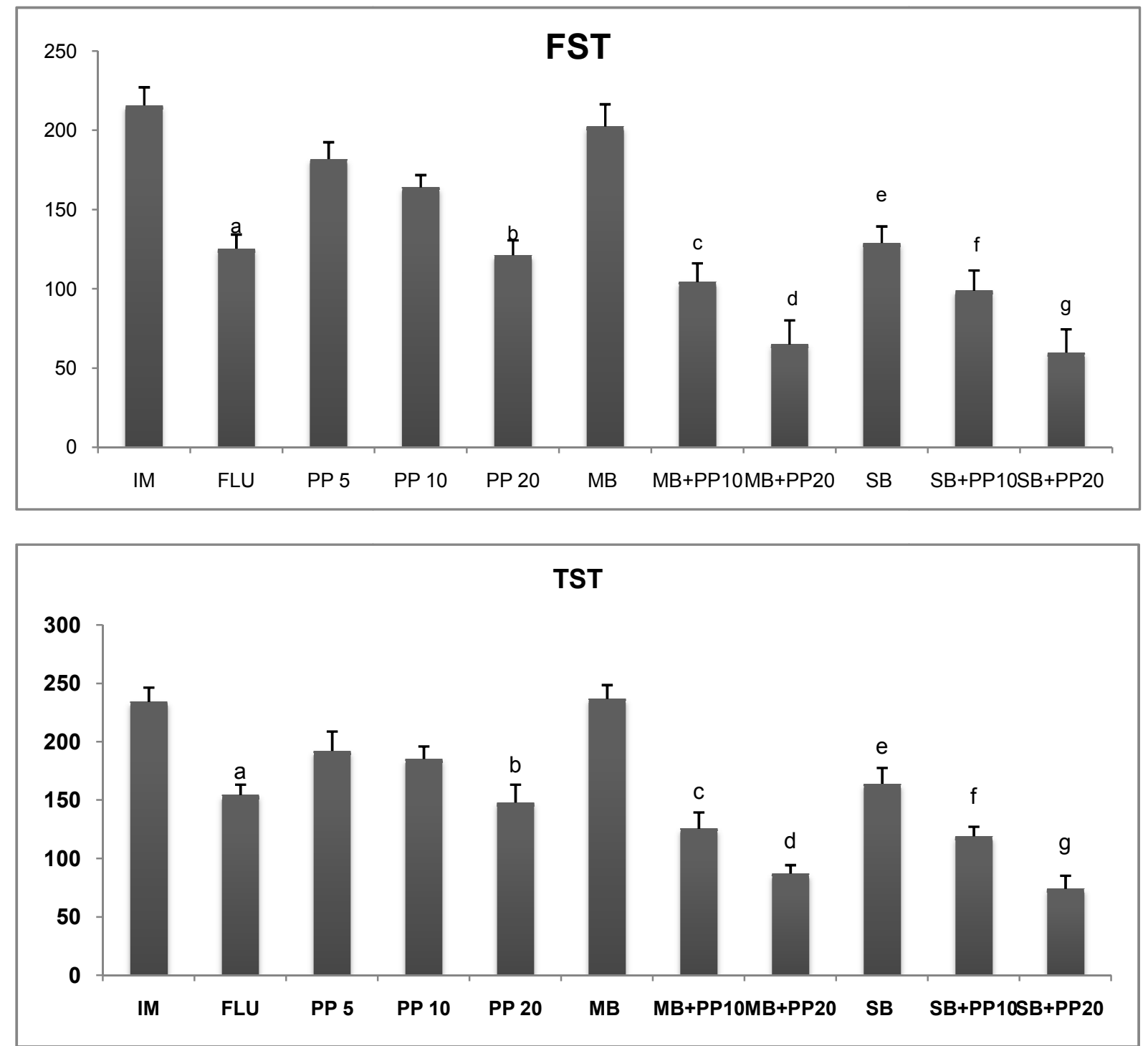

Values are expressed as mean \pm S.E. Data was analyzed by one way ANOVA followed by Tukey's Post Hoc Test,in FST $F$ $(10,55)=19.60$, TST $F(10,55)=19.3 ; p<0.0001, a=p<0.001$ significant difference from immobilized group, $b=p<0.001$ significant difference from immobilized group, $c=p<0.05$ significant difference from PP $(10 \mathrm{mg} / \mathrm{kg})$ treated group, $d=p<$ 0.05 significant difference from PP $(20 \mathrm{mg} / \mathrm{kg})$ treated group, $e=p<0.001$ significant from immobilized group, $f=p<0.05$ significant from PP $(10 \mathrm{mg} / \mathrm{kg})$ treated group, $\mathrm{g}=\mathrm{p}<0.05$ significant from PP $(20 \mathrm{mg} / \mathrm{kg})$ treated group. UnS: unstressed ,IM: Immobilization, PP: Piperine, MB: Methylene blue, SB: SB-203580. Doses mentioned are in $\mathrm{mg} / \mathrm{kg}$

Figure 1: Effect of different treatmens on immobility time on stressed mice in Forced swim test(FST) as well as Tail Suspension Test (TST), $\mathrm{n}=6$ in each group. 
Harshita Jain et alo,

As shown in figure 2 SB-203580 significantly decreased immobility time in stressed group. A significant decrease in immobility time was observed when administered in combination with PP $(20 \mathrm{mg} / \mathrm{kg})$. Table 2 shows that there is no significant change in locomotor activity as compared to vehicle treated group and immobilized group with all treatments.

Treatments on unstressed group have no significant change in plasma nitrite level. As shown in figure 2 Fluoxetine $(15 \mathrm{mg} / \mathrm{kg})$, PP $(20 \mathrm{mg} / \mathrm{kg})$ significantly decreased plasmanitrite levels as compared to immobilized group. Combination of Methylene blue $(15 \mathrm{mg} / \mathrm{kg})$ and Methylene blue $(10,20 \mathrm{mg} / \mathrm{kg})$ significantly decreased plasma nitrite levels as compared to PP $(10 \mathrm{mg} / \mathrm{kg})$ treated group. A significant reduced levels has been also observed in SB-203580 $(1 \mathrm{mg} / \mathrm{kg})$ in combination with $\operatorname{PP}(10,20 \mathrm{mg} / \mathrm{kg})$ as compared to per se SB-203580(1 mg/kg).
Sci. Technol. Arts Res. J., Jan-March 2015, 4(1): 109-114

Table 2: The effect of different treatments on locomotor activity in stressed mice $(n=6)$

\begin{tabular}{ccc}
\hline Treatment & $\begin{array}{c}\text { Dose } \\
\text { (mg/kg, i.p) }\end{array}$ & $\begin{array}{c}\text { Locomotor activity counts } \\
\text { (Mean } \pm \text { SEM) }\end{array}$ \\
\hline IM & $6 h$ & $156.1 \pm 13.0$ \\
FLU & 15 & $137.1 \pm 16$ \\
PP & 5 & $154.3 \pm 15$ \\
PP & 10 & $137.5 \pm 11$ \\
PP & 20 & $119.2 \pm 10$ \\
MB & 15 & $149.3 \pm 19.6$ \\
MB + PP & $15+10$ & $138.5 \pm 16.7$ \\
MB + PP & $15+20$ & $159.3 \pm 15.8$ \\
SB & 1 & $141.6 \pm 10$ \\
SB + PP & $1+10$ & $155.3 \pm 14$ \\
SB + PP & $1+20$ & $143.8 \pm 18.5$ \\
\hline
\end{tabular}

Effect of different treatments on locomotor activity in stressed mice expressed in Locomotor activity counts in test for locomotor activity. UnS: unstressed, IM: Immobilization, PP: Piperine, MB: Methylene blue, SB: SB-203580. Doses mentioned are in $\mathrm{mg} / \mathrm{kg}$.

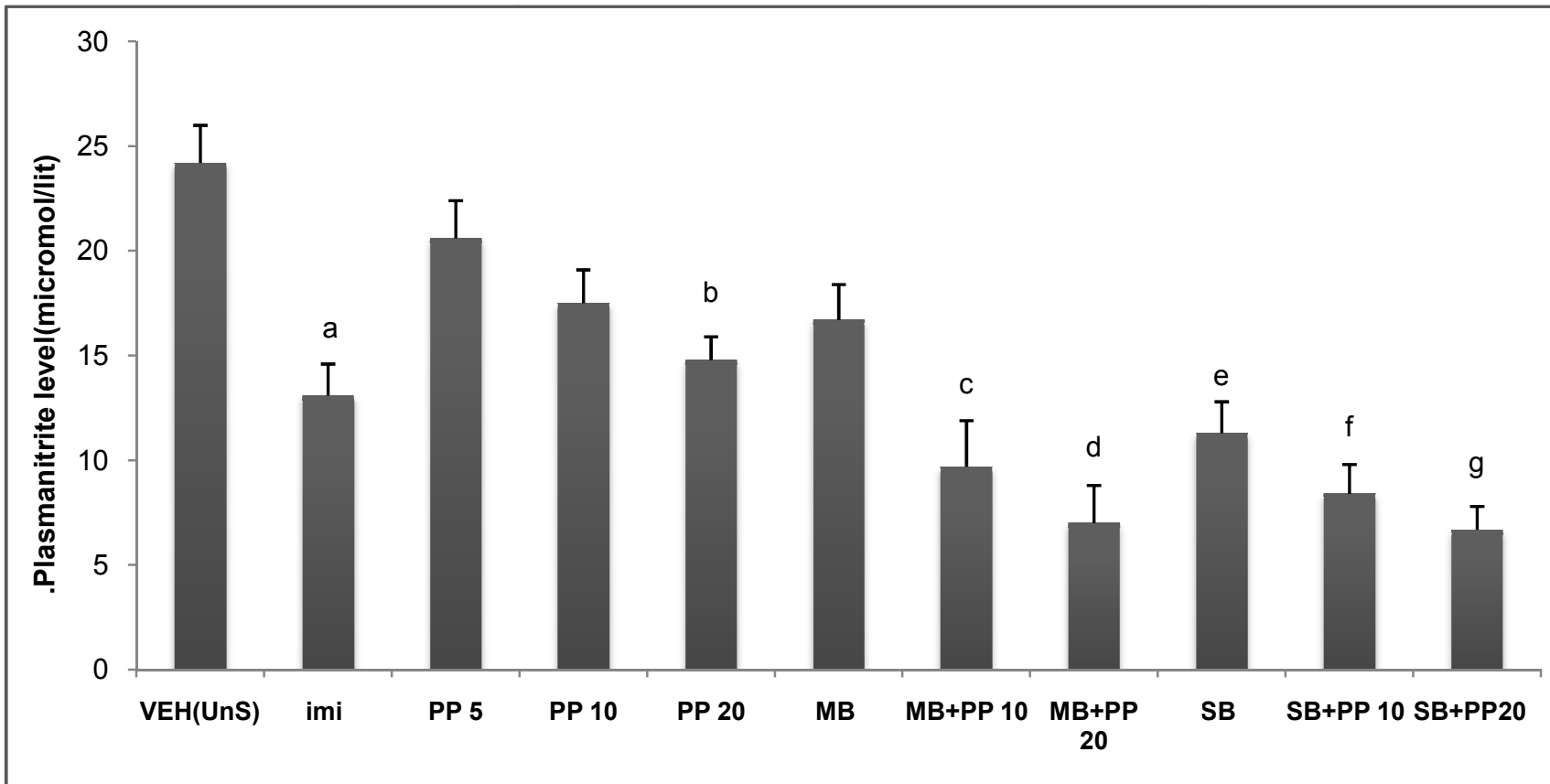

Values are expressed as Mean \pm S.E. Data was analyzed by one way ANOVA followed by Tukey's Post Hoc Test, $F$ (10, 55) = 19.3; $p$ $<0.0001, a=p<0.001$ significant difference from immobilized group, $b=p<0.01$ significant difference from immobilized group, $c=p$ $<0.05$ significant difference from PP $(10 \mathrm{mg} / \mathrm{kg})$ treated group, $\mathrm{d}=\mathrm{p}<0.05$ significant difference from PP $(20 \mathrm{mg} / \mathrm{kg})$ treated group, e $=p$ $<0.001$ significant from immobilized group, $f=p<0.05$ significant from PP $(10 \mathrm{mg} / \mathrm{kg})$ treated group, $g=p<0.05$ significant from PP $(20 \mathrm{mg} / \mathrm{kg})$ treated group. UnS: unstressed ,IM: Immobilization, PP: Piperine, MB: Methylene blue, SB: SB-203580. Doses mentioned are in $\mathrm{mg} / \mathrm{kg}$.

Figure 2: The effect of different treatments on plasma nitrite levels $(\mu \mathrm{mol} / \mathrm{L})$ in stressed mice $(\mathrm{n}=6)$

\section{DISCUSSION}

The results of the present study indicate the potential of antidepressant effect of piperine in stressed mice, exposed to $6 \mathrm{~h}$ immobilization stress. MB, an inhibitor of cGMP, a downstream component of NO signaling potentiated the effect of sub-effective dose of PP. Further, SB-203580, a potent inhibitor of p38MAPkinase, an upstream component of iNOS formation after stress, is also observed to enhance the effect of PP in stressed mice.

Piperine, being an inhibitor of iNOS mRNA expression has been successful to prevent the immobilization stressinduced increase in plasma nitrite levels in stressed mice. Similarly, SB-203580 per se has decreased plasma nitrite levels and produced antidepressant effect in stressed mice. cGMP is a second messenger in neuronal cell-cell communication and in cell-cell signaling from between presynaptic fibres as well as between postsynaptic structures (Southam and Garthwaite, 1993). The present study showed that MB, an inhibitor of CGMP, significantly produced antidepressant effect in unstressed mice. An important finding of the present study is that $M B$ enhanced the antidepressant effect of PP in stressed mice at a dose, previously reported to produce antidepressant effect (Eroğlu and Cağlayan, 1997). The possible mechanism of MB-enhanced antidepressant effect of PP can be explained by its influence on NOcGMP signaling pathway, thereby, preventing the further downstream signaling of nitriergic stimulus induced by immobilization stress. The antidepressant effect of MB per 
Harshita Jain et alo,

se as well as pretreatment combination with PP in unstressed mice indicates only the effect produced by per se treatment of MB.

Mice were subjected to testing for induction of depression by using two most commonly used and reliable models like Tail suspension test and Forced swim test. Pathophysiologic indicator of immobilization stressinduced depression was measured in form of plasma nitrite, a stable metabolic product of nitric oxide, which has been implicated in underlying pathology of depression. The salient findings of the study can be summarized saying Mice subjected to FST and TST experience the immobility, however, there was no change in plasma nitrite levels in these mice.

Mice, subjected to $6 \mathrm{~h}$ immobilization stress experienced enhanced depression as indicated by an increase in duration of immobility in behavioral paradigms. This increase in duration of immobility was accompanied by an increase in plasma nitrite levels in these stressed mice.

Administration of Piperine, in unstressed mice did not produce any change in duration of immobility in mice, whereas, in stressed mice, Piperine served to decrease the immobility time as well as plasma nitrite levels.

Methylene blue, a direct inhibitor of NO and its downstream component; cGMP markedly produced antidepressant activity in unstressed mice and decreased plasma nitrite levels. On the other hand, in stressed mice, MB per se could not exert any significant antidepressant effect. However, MB served to enhance the effect of Piperine in stressed mice.

SB-203580, an inhibitor of p38MAPkinase, served to produce a significant antidepressant effect in stressed mice, but not in unstressed mice. Similarly, it decreased plasma nitrite in stressed mice, but not in unstressed mice. Further, SB-203580 served to enhance the effect of Piperine in stressed mice and could not produce any change in observed effect of Piperine alone in unstressed mice.

\section{CONCLUSIONS}

These results obtained by these treatments administered in the present study can be attributed to their effects on depression since they had no any effects on locomotor activity. Further, they also served to directly influence the plasma nitrite levels, an indicator of NO production and a pathophysiologic mediator(s) of depression, which further serve to validate the action of treatments on depression symptoms rather than on locomotor aspect involved in behavior of mice in both the behavioral paradigms used in the present study.

\section{Conflict of Interest}

Conflict of interest none declared.

\section{REFERENCES}

André, M., Latado, H., Felley-Bosco, E. (2005). Inducible nitric oxide synthase-dependent stimulation of PKGI and phosphorylation of VASP in human embryonic kidney cells. Biochemical Pharmacology 69:595-602.
Sci. Technol. Arts Res. J., Jan-March 2015, 4(1): 109-114

Baranano, D.E., Ferris, C.D., Snyder, S.H. (2001). A typical neural messengers. Trends in Neurosciences 24: 99-106.

Bhattacharya, S.K., Bhattacharyya D. (1982). Effect of restraint stress on rat brain serotonin Journal of Biosciences 4: 269.

Bhutani, M.K., Bishnoi, M., Kulkarni, S.K (2008). Antidepressant like effect of curcumin and its combination with piperine in unpredictable chronic stress-induced behavioral, biochemical and neurochemical changes. Pharmacology Biochemistry and Behavior 92(1): 39-43.

Paola De Cesaris, Donatella Starace, Giuseppe Starace, Antonio Filippini, Mario Stefanini, and Elio Ziparo. (1999). Activation of Jun N-terminal Kinase/Stress-activated ProteinKinase Pathway by Tumor Necrosis Factor a Leads to Intercellular Adhesion Molecule-1 Expression. Journal of Biological Chemistry 274(41): 28978-28982.

Da Silva, G.D., Matteussi, A.S., dos Santos, A.R., Calixto, J.B., Rodrigues, A.L. (2000). Evidence for dual effects of nitric oxide in the forced swimming test and in the tail suspension test in mice. Neuroreport 11: 3699-3702.

De Oliveira, R.M., Del Bel, E.A., Mamede-Rosa, M.L., Padovan, C.M., Deakin, J.F., Guimarães, F.S. (2000). Expression of neuronal nitric oxide synthase mRNA in stress-related brain areasvafter restraint in rats. Neuroscience Letters 289:123-126.

De Oliveira, R.M.W., Guimarães, F.S., Deakin, J.F.W. (2008). Expression of neuronal nitric oxide synthase in the hippocampal formation in affective disorders. Brazilian Journal of Medical and Biological Research 41(4):333341.

Douma, S.L., Husband, C., O'Donnell, M.E., Barwin, B.N., Woodend, A.K. (2005). Estrogen-related Mood Disorders Reproductive Life Cycle Factors. Advances in Nursing Science 28(4): 364-375.

Dzoljic, E., De Vries, R., Dzoljic, M.R.( 1997). New and potent inhibitors of nitric oxide synthase reduce motor activity in mice. Behavioural Brain Research 87: 209-212.

Eroglu, L., Caglayan, B. (1997). Anxiolytic and antidepressant properties of methylene blue in animal models. Pharmacological Research 36: 381-385.

Esch, T., Stefano, G.B., Fricchione, G.L., Benson, H. (2002). Stress in Cardiovascular Diseases. Medical Science Monitor 8(5): 93-101.

Esch, T., Stefano, G.B., Fricchione, G.L., Benson, H. (2002). The role of stress in neurodegenerative diseases and mental disorders. Neuroendocrinology Letters 22(3):199208.

Finkel, M.S., Laghrissi-Thode, F., Pollock, B.G., Rong, J. (1996). Paroxetine is a novel nitric oxide synthase inhibitor. Psychopharmacol Bull 32(4): 653-658.

Gilhotra, N., Dhingra, D. (2009). Involvement of NO-cGMP pathway in anti-axiety effect of aminoguanidine in stressed mice. Progress in Neuro-Psychopharmacology \& Biological Psychiatry 33:1502-507.

Gow, A.J., Farkouh, C.R., Munson, D.A., Posencheg, M.A., Ischiropoulos, H.(2004). Biological significance of nitric oxide-mediated protein modifications. American Journal of Physiology - Lung Cellular and Molecular Physiology 287(2): L262-268.

Green, L.C., Wagner, D.A., Glogowski, J., Skipper, P.L., Wishnock, J.S., Tannenbaum, S.R. (1982). Analysis of Nitrate, nitrite, and [N-15N]-labelled nitrate in biological fuids. Anals of Biochemistry 126:131-138. 


\section{Harshita Jain et al.,}

Harkin, A., Bruce, K.H., Craft, B., Paul, I.A.(1999). Nitric oxide synthase inhibitors have antidepressant-like properties in mice. 1. Acute treatments are active in the forced swim test. Europian Journal of Pharmacology 372: 207-213.

Holscher, C. (1997). Nitric oxide, the enigmatic neuronal messenger: its role in synaptic plasticity. Trends in Neurosciences 20(7): 298-303.

Jefferys, D., Funder, J. (1996). Nitric oxide modulates retention of immobility in the forced swimming test in rats. Europian Journal of Pharmacology 295:131-135.

Jopek, R., Kata, M., Nowak, G. (1999). The activity of rat brain nitric oxide synthase following chronic antidepressant treatment. Acta Poloniae Pharmaceutica 56(4): 307-310.

Madrigal, J.L., Hurtado, O., Moro, M.A., Lizasoain, I., Lorenzo, P., Castrillo, A., Boscá, L., Leza, J.C. (2002). The increase in TNF-alpha levels is implicated in NFkappaB activation and inducible nitric oxide synthase expression in brain cortex after immobilization stress. Neuropsychopharmacology 26(2):155-163.

Mutlu, O., Ulak, G., Laugeray, A., Belzung, C. (2009). Effects of neuronal and inducible NOS inhibitor 1-[2(trifluoromethyl) phenyl] imidazole (TRIM) in unpredictable chronic mild stress procedure in mice. Pharmacology Biochemistry \& Behavior 92(1): 82-87.

Nagao, K., Takenaka, S., Yamaji, R., Inui, H., Nakano, Y. (2003). Nitric oxide synthase induction, cGMP elevation, and biopterin synthesis in vascular smooth muscle cells stimulated with interleukin-1beta in hypoxia. Journal of Biochemistry 133(4): 501-505.

Nelson, R.J., Demas, G.E., Huang, P.L., Fishman, M.C., Dawson, V.L., Dawson, T.M,, Snyder, S.H. (1995) Behavioural abnormalities in male mice lacking neuronal nitric oxide synthase. Nature 378:383-386.

Porsolt, R.D. (1979). Animal model of depression. Biomedicine 30(3):139-40.

Schuman, E.M., Madison, D.V. (1994). Nitric oxide and synaptic function. Annual Review of Neuroscience 17:153-183.
Sci. Technol. Arts Res. J., Jan-March 2015, 4(1): 109-114

Sevgi, S., Ozek, M., Eroglu, L (2006). L-NAME prevents anxiety-like and depression-like behavior in rats exposed to restraint stress. Methods and Findings in Experimental and Clinical Pharmacology 28(2):95-99.

Snyder, S.H., Bredt, D.S. (1991). Nitric oxide as a neural messenger. Trends in Pharmacological Sciences 12: 125128.

Steru, L., Chermat, R., Thierry, B., Simon, P.( 1985). The tail suspension test: a new method for screening antidepressants in mice. Psychopharmacology (Berl) 85(3): 367-70.

Michel, T., Feron, O. (1997). Nitric oxide synthases: which, where, how, and why. Journal of Clinical Investigation 100(9): 2146-2152.

Tsuchiya, T., Kishimoto, J., Koyama, J., Ozawa, T. (1997). Modulatory effect of L-NAME, a specific nitric oxide synthase (NOS) inhibitor, on stress-induced changes in plasma adrenocorticotropic hormone (ACTH) and corticosterone levels in rats: physiological significance of stress-induced NOS activation in hypothalamic-pituitaryadrenal axis. Brain Research 776(1-2): 68-74.

Wegener, G., Volke, V., Harvey, B.H., Rosenberg, R. (2003). Local, but not systemic administration of serotonergic antidepressants decreases hippocampal nitric oxide synthase activity. Brain Research 959:128-133.

Wiley, J.L., Cristello, A.F., Balster, R.L. (1995). Effects of siteselective NMDA receptor antagonists in an elevated plusmaze model of anxiety in mice. Europian Journal of Pharmacology 294:101-107.

Yildiz, F., Erden, B.F., Ulak, G., Utkan, T., Gacar, N. (2000). Antidepressant-like effect of 7-nitroindazole in the forced swimming test in rats. Psychopharmacology (Berl) 149: 41-44.

Yildiz, F., Ulak, G., Erden, B.F., Gacar, N. (2000). Anxiolyticlike effects of 7-nitroindazole in the rat plus-maze test. Pharmacology Biochemistry and Behavior 65:199-202 